\title{
Redox and Antioxidant Modulation of Circadian Rhythms: Effects of Nitroxyl, N-Acetylcysteine and Glutathione
}

\author{
Santiago Andrés Plano ${ }^{1,+}+{ }^{\oplus}$, Fernando Martín Baidanoff ${ }^{2,+}{ }^{+}$Laura Lucía Trebucq ${ }^{2}$, Sebastián Ángel Suarez ${ }^{3}{ }^{\circledR}$, \\ Fabio Doctorovich ${ }^{3}$, Diego Andrés Golombek ${ }^{2, *}$ (1) and Juan José Chiesa ${ }^{2}$ \\ 1 Institute for Biomedical Research (BIOMED), Catholic University of Argentina (UCA) and National Scientific \\ and Technical Research Council (CONICET), C1107CABA Buenos Aires, Argentina; \\ santiagoplano@uca.edu.ar \\ 2 Laboratorio de Cronobiología, Departamento de Ciencia y Tecnología, Universidad Nacional de Quilmes (UNQ) \\ Consejo Nacional de Investigaciones Científicas y Técnicas (CONICET), Roque Sáenz Peña 352, \\ B1876BXD Bernal, Argentina; fbaidanoff@gmail.com (F.M.B.); laura.trebucq@gmail.com (L.L.T.); \\ juan.chiesa@unq.edu.ar (J.J.C.) \\ 3 Departamento de Química Inorgánica, Analítica y Química Física/INQUIMAE-CONICET, \\ Facultad de Ciencias Exactas y Naturales, Universidad de Buenos Aires, Ciudad Universitaria, Pab. II, \\ C1428EHA Buenos Aires, Argentina; seba@qi.fcen.uba.ar (S.Á.S.); fabio.doctorovich@gmail.com (F.D.) \\ * Correspondence: dgolombek@unq.edu.ar; Tel.: +54-113657100 \\ + These authors contributed equally to this work.
}

\section{check for} updates

Citation: Plano, S.A.; Baidanoff, F.M.; Trebucq, L.L.; Suarez, S.Á.;

Doctorovich, F.; Golombek, D.A.;

Chiesa, J.J. Redox and Antioxidant Modulation of Circadian Rhythms: Effects of Nitroxyl, N-Acetylcysteine and Glutathione. Molecules 2021, 26, 2514. https://doi.org/10.3390/ molecules26092514

Academic Editors: Cristina Maccallini and Rosa Amoroso

Received: 21 March 2021

Accepted: 23 April 2021

Published: 26 April 2021

Publisher's Note: MDPI stays neutral with regard to jurisdictional claims in published maps and institutional affiliations.

Copyright: (c) 2021 by the authors. Licensee MDPI, Basel, Switzerland. This article is an open access article distributed under the terms and conditions of the Creative Commons Attribution (CC BY) license (https:// creativecommons.org/licenses/by/ $4.0 /)$.
Abstract: The circadian clock at the hypothalamic suprachiasmatic nucleus (SCN) entrains output rhythms to 24-h light cycles. To entrain by phase-advances, light signaling at the end of subjective night (circadian time 18, CT18) requires free radical nitric oxide (NO•) binding to soluble guanylate cyclase (sGC) heme group, activating the cyclic guanosine monophosphate (cGMP)-dependent protein kinase (PKG). Phase-delays at CT14 seem to be independent of NO•, whose redox-related species were yet to be investigated. Here, the one-electron reduction of NO• nitroxyl was pharmacologically delivered by Angeli's salt (AS) donor to assess its modulation on phase-resetting of locomotor rhythms in hamsters. Intracerebroventricular AS generated nitroxyl at the SCN, promoting phasedelays at CT14, but potentiated light-induced phase-advances at CT18. Glutathione/glutathione disulfide (GSH/GSSG) couple measured in SCN homogenates showed higher values at CT14 (i.e., more reduced) than at CT18 (oxidized). In addition, administration of antioxidants $\mathrm{N}$-acetylcysteine (NAC) and GSH induced delays per se at CT14 but did not affect light-induced advances at CT18. Thus, the relative of NO• nitroxyl generates phase-delays in a reductive SCN environment, while an oxidative favors photic-advances. These data suggest that circadian phase-locking mechanisms should include redox SCN environment, generating relatives of $\mathrm{NO} \bullet$, as well as coupling with the molecular oscillator.

Keywords: suprachiasmatic nuclei; cGMP; Angeli's salt; reactive nitrogen species

\section{Introduction}

The mammalian circadian clock at the hypothalamic suprachiasmatic nuclei (SCN) orchestrates daily rhythms in a broad range of behavioral and physiological processes, driving autonomic and endocrine outputs which coordinate a network of oscillators in peripheral tissues [1]. This is achieved by the entrainment (i.e., phase-shifting) of the SCN oscillator activity to equal the 24-h light-dark cycle. Interacting transcriptionaltranslational feedback loops (TTFLs) of clock genes generate core oscillator activity at the SCN cells and most peripheral tissues. A transcriptional activator, formed by circadian locomotor output cycles kaput (CLOCK) and brain and muscle aryl hydrocarbon receptor nuclear translocator-like protein 1 (BMAL1) heterodimer, binds to enhancer elements at the promoter of repressor clock genes period (per) 1, 2, and 3, and cryptochrome (cry) 1 and 2, increasing their transcriptional activity. In turn, PERs and CRYs proteins accumulate in 
the cytoplasm and heterodimerize, generating transcriptional repressors by interfering with the CLOCK:BMAL heterodimers, closing the cycle each $24 \mathrm{~h}$. Entrainment of the SCN clock to the light-dark cycles involves the communication of photic information through several neurotransmitters and signal transduction pathways, whose endpoint effectors converge to modify the activity of clock genes at the transcriptional level [2]. Moreover, the TTFL circadian clockwork might be modulated by the redox state. Indeed, several redox pairs have been shown to interact with either circadian clock proteins or transcriptional regulators in vitro $[3,4]$. The $\mathrm{SCN}, \mathrm{NADP}+/ \mathrm{NADPH}, \mathrm{FAD}+\mathrm{FADH}$, and dehydroascorbic acid/ascorbic acid redox couples, as well as the global protein glutathiolation, exhibit circadian oscillations, while the resting electrical activity of $\mathrm{SCN}$ neurons is also sensitive to oxidants and reductants [5].

Brief light stimulation during the circadian night (i.e., the time of behavioral activity in nocturnal rodents) generates a phase-shift of the SCN clock, and thereby its behavioral and physiological rhythmic outputs [6]. The specific circadian time (CT) at which the light pulse is applied is determinant of whether phase-delays or advances are induced. At CT14 (i.e., $2 \mathrm{~h}$ after locomotor activity onset, CT12), a phase-delay of locomotor rhythm is generated, while phase-advances occur after stimulation at the late circadian night at CT18. Phase-shifts are transduced by the glutamatergic influx through efferents from the retinal ganglion cells to ventral SCN neurons, which promotes calcium influx through glutamate-N-methyl-D-aspartate receptors (NMDAr) and triggers calcium-dependent calmodulin-kinase phosphorylation of the nitric oxide synthase (nNOS), increasing its activity [7]. Downstream, the pathway for advances proceeds through NO• coordination of regulatory ferrous heme on the soluble guanylyl cyclase (sGC), increasing cGMP synthesis and, subsequently, the cGMP-dependent protein kinase (PKGII) activity [8] to phosphorylate its dependent substrate [9]. At CT14, circadian phase-delays proceed through other pathways (e.g., adenylate cyclase/cyclic adenosine monophosphate (cAMP)/cAMP-activated protein kinase (PKA)) [2] activated by calcium influx through the aperture of endoplasmic ryanodine type 2 receptor channels [10]. Downstream, both pathways converge at cAMP-responding element-binding protein (CREB) phosphorylation [11] to activate CRE-mediated period 1-2 transcription [12,13], thereby setting the phase of the clock.

Various drugs can modulate circadian entrainment targeting NO• transduction, including organic nitroso derivatives such as S-Nitroso-N-acetylpenicillamine (SNAP, an S-nitrosothiol), or $\mathrm{N}$-nitrosomelatonin (NOMel), both acting as NO• donors [14,15]. While $\mathrm{NO} \bullet$ generation by NOMel at the SCN only potentiates photic phase-advances-and doesn't delay even at high doses [15] — administration of SNAP potentiates both photic delays and advances [14]. At high doses SNAP can work as an NO• donor, increasing cGMP, but low doses generate S-nitrosation with opposite effects in cardiomiocytes [16]. On the other hand, the nNOS antagonist N-nitro-L-arginine methyl ester L-NAME attenuates both phase-advances and phase-delays of locomotor activity rhythms in hamsters [14,17]. Extracellular scavenging of NO• with 2-Phenyl-4,4,5,5-tetramethylimidazoline-1-oxyl 3-oxide (PTIO) blocks photic phase-advances, but not delays, which demonstrates its role as a paracrine messenger, by decreasing ventral-dorsal communication of light message at the SCN [18].

A hypothesis for circadian pathway bifurcation downstream of $\mathrm{NO} \bullet$ [19] states that the photic activation of sGC hemoprotein occurs with diffusible, long-range (i.e., far from its nNOS source) NO• concentrations [20,21], which, despite being a highly diffusible, membrane-permeable gaseous messenger, participates in an array of redox-dependent, secondary reactive nitrogen species, as S-nitrosothiols (i.e., S-nitrosated glutathione, GSNO), nitroxyl anion $\left(\mathrm{NO}^{-}\right)$, and metalnitrosyl complexes [22]. In addition, redox forms of $\mathrm{NO} \bullet$ may act in so-called redox-dependent signaling to form S-nitrosation (i.e., the addition of a nitroso group by condensation of a thiol and the one-electron oxidation of $\mathrm{NO} \bullet$, nitrous acid) $[20,23]$. The one-electron reduced (and protonated at physiological $\mathrm{pH}$ ) relative of $\mathrm{NO} \bullet$ nitroxyl (HNO, azanone, nitrosylhydride, among other names) can be generated 
by a number of biological processes: $\mathrm{HNO}$ is a by-product of S-nitrosothiols reaction with cysteine thiols [24] and is even produced by nNOS [25]. Pharmacologically, it can be generated by the decomposition of sodium trioxodinitrate $\left(\mathrm{Na}_{2}\left[\mathrm{~N}_{2} \mathrm{O}_{3}\right]\right.$ Angeli's salt, AS) together with sodium nitrite at physiological conditions [26]. HNO is widely studied in the cardiovascular system [27], and can be easily oxidized to NO• at physiological

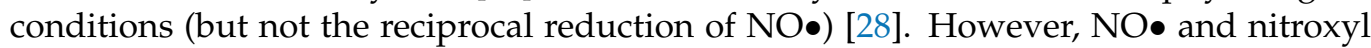
exhibit differential reactivity toward metalloproteins, as well as different thiophilicity depending on redox intermediates, which might explain their distinctive physiological roles [28]. Moreover, while NO• increases cGMP through sGC, HNO activates a calcitonin gene-related peptide [29], increasing cAMP, and also modulates calcium channels and ryanodine receptors [30]. Thus, HNO is proposed as a signaling molecule with more distinctive effects than $\mathrm{NO} \bullet$ and is thus worthy of continued study regarding its role in circadian entrainment.

In this context, we investigated the role of NO• relative nitroxyl in the circadian clock entrainment under pharmacological administration of Angeli's Salt, a diazeniumdiolatebased nitroxyl donor. In addition, the antioxidants $\mathrm{N}$-acetylcysteine (NAC) and glutathione (GSH) were used to test whether the pharmacological modulation of the SCN-redox environment can affect circadian entrainment. In this way, we provide evidence of the role of putative redox forms of $\mathrm{NO \bullet}$, as well as the redox modulation of $\mathrm{SCN}$, driving this key circadian function.

\section{Results}

\subsection{Effect of the Nitroxyl Donor Angeli's Salt on Phase-Shifts of Locomotor Rhythms}

Phase-shifting experiments under DD conditions were performed to assess the effect of Angeli's Salt (AS) administration on photic entrainment. AS, a well-known nitroxyl donor, was delivered i.c.v. $(1 \mu \mathrm{L}, 100 \mu \mathrm{M}) 5 \mathrm{~min}$ before a subsaturant LP at CT14 (to induce delays) or CT18 (for advances). We found a circadian-dependent effect of AS over circadian phase-shifting. At CT14, this nitroxyl donor induced a phase-delay when administered alone in the dark, as compared with the vehicle (AS dark: $66.8 \mathrm{~min} \pm 26.3 \mathrm{~min}, n=5$; Vehicle dark: $22.0 \mathrm{~min} \pm 13.7 \mathrm{~min}, n=9 ; p<0.05$ Tukey's multiple comparisons test) (Figure 1A). AS did not affect light-induced phase-delays at CT14 (AS LP: $101.1 \mathrm{~min} \pm 38.4 \mathrm{~min}, n=7$; Vehicle LP: $97.4 \mathrm{~min} \pm 28.2 \mathrm{~min}, n=5$, respectively; $p=$ ns Tukey's multiple comparisons test) (Two-way ANOVA; LP $p<0.0001, \mathrm{~F}=24.82$, $\mathrm{DFn}=1$, $\mathrm{DFd}=22$; Drug $p>0.05, \mathrm{~F}=4.85$; interaction $p=\mathrm{ns}, \mathrm{F}=3.47$ ) (Figure 1A). On the other hand, at CT18 AS administration potentiated the effect of light, as it significantly increased phase-advances as compared with the vehicle (AS LP: $251.7 \mathrm{~min} \pm 75.9 \mathrm{~min}, n=4$; Vehicle LP: $116.2 \mathrm{~min} \pm 53.2 \mathrm{~min}, n=4$, respectively; $p>0.001$ Tukey's multiple comparisons test) (Figure 1B), but did not generate any effect on the circadian phase when delivered alone (AS Dark: $0.3 \mathrm{~min} \pm 8.1 \mathrm{~min}, n=4$; Vehicle Dark: $4.7 \mathrm{~min} \pm 34.9 \mathrm{~min}, n=8$, respectively; $p=$ ns Tukey's multiple comparisons test) (Two-way ANOVA; LP $p<0.0001, \mathrm{~F}=73.55$, DFn = 1, DFd = 16; Drug $p>0.01, \mathrm{~F}=9.03$; interaction $p<0.01, \mathrm{~F}=10.46)$. These results indicate that AS modulates light-induced phase-shifts at CT18 but has no effect on light signaling at CT14 (i.e., AS modulates lightinduced phase-advances but not light-induced phase-delays). On the other hand, AS administration at CT14, without LP, has a photic-like effect-inducing phase-delays of the circadian rhythm. 

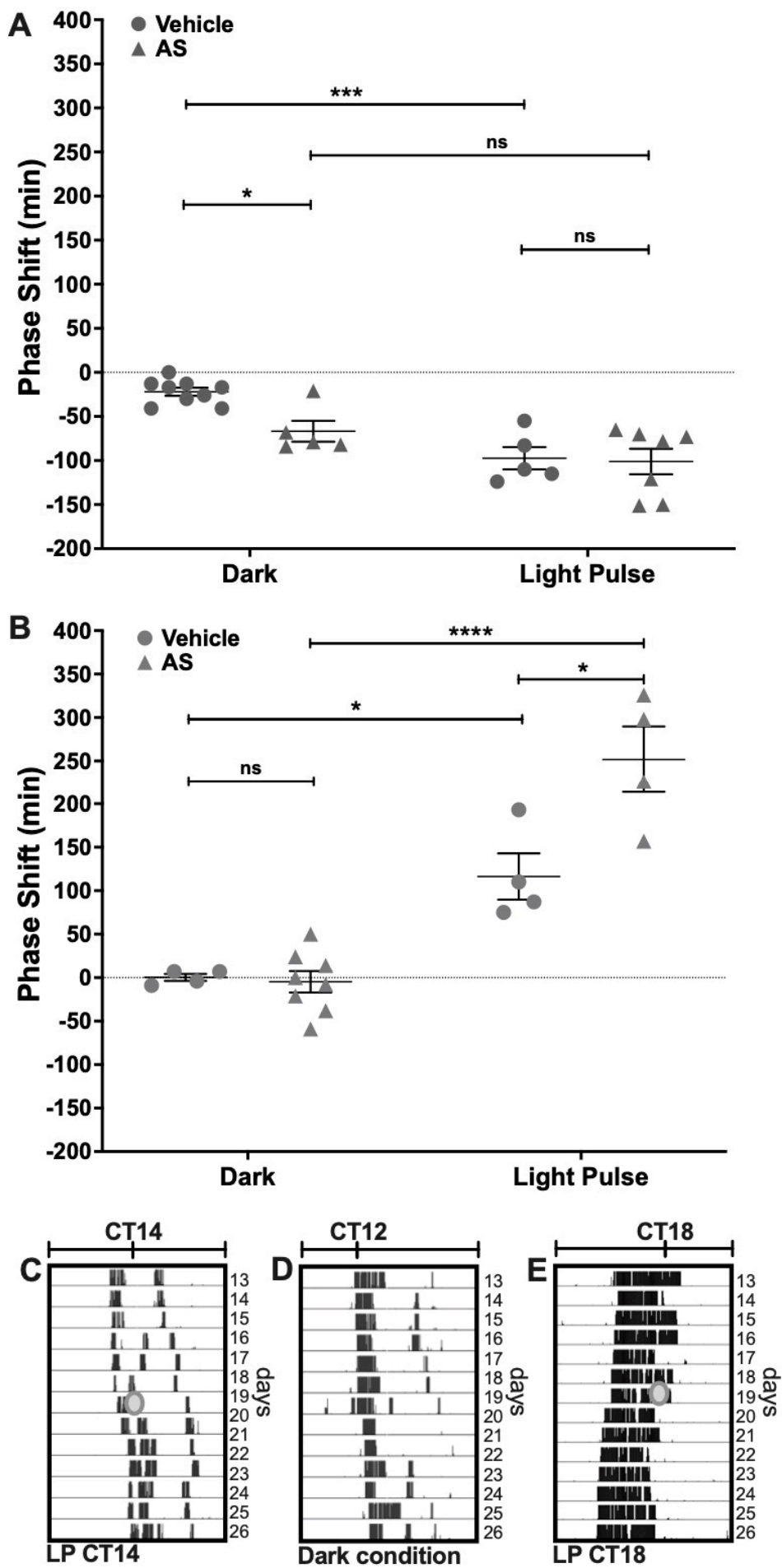

Figure 1. Effect of the nitroxyl donor AS on phase changes induced by light. Hamsters in constant darkness conditions, treated with an i.c.v injection of vehicle or $100 \mu \mathrm{M}$ AS, 5 min before a subsaturant light pulse (LP, $10 \mathrm{~min}, 50 \mathrm{lux}$ ) at two CTs: (A) CT14 and (B) CT18. Control animals (Dark) received only pharmacological treatment without the light pulse. Phase changes are shown as mean \pm SEM. Two-way ANOVA, followed by Tukey's multiple comparisons test, ns = not significant; ${ }^{*} p<0.05$; *** $p<0.001 ;{ }^{* * * *} p<0.0001$. CT14 Dark: Veh $n=9$, AS $n=5$; CT14 LP: AS + LP $n=7$, Veh + PL; CT18 Dark: Veh $n=4$, AS $n=7$; CT18 LP: Veh + LP and AS + LP $n=5$. (C-E) are representative actograms showing: (C) the effect of a light pulse at CT14, inducing a phase-delay in the circadian locomotor rhythms; (D) the phase of an animal without light stimulation during the subjective night; and (E) the effect of light stimulation at CT18, which induces a phase-advance. The grey circle indicates the day and time of the LP. 


\subsection{Electrochemical Detection of Nitroxyl (HNO) In Vivo at the SCN}

Decomposition of AS is known to produce both HNO and NO• [31,32]. To verify if $\mathrm{HNO}$ was effectively generated at physiological conditions, time-resolved electrochemical quantification was performed in vivo at the SCN in anesthetized hamsters. Raw data series showed changes in current intensity measured in a representative individual for detecting HNO concentration at the SCN. Smoothed data allowed paired measures at baseline (vehicle-treated) and after AS microinjection in the same individual (Figure 2A). Differences in current intensity were calculated as the difference between maximum current values after AS treatment and baseline values. Current intensity ( $\mu$ Amperes, $\mu \mathrm{A})$ showed increased values after both $400 \mathrm{pmol}$ and $800 \mathrm{pmol}$ doses. A significant difference in this current increment was found regarding AS concentration (Figure 2B), showing higher increment for 800 pmol $(0.111 \mu \mathrm{A} \pm 0.022 \mu \mathrm{A})$ as compared with 400 pmol $(0.039 \mu \mathrm{A} \pm 0.033 \mu \mathrm{A})$ $(p<0.05$ paired Student's $t$-test; $t=5.14 ; \mathrm{df}=3)$, indicating HNO generation by AS in a dose-dependent manner. Using a similar concentration order (400 and $800 \mathrm{pmol})$ as that used for phase/shifting experiments $(100 \mathrm{pmol})$ these results allowed us to verify that $\mathrm{HNO}$ is pharmacologically generated by decomposition of AS after i.c.v. delivery of the drug in the SCN.

\subsection{Measurement of the Redox Pair GSH-GSSG at the SCN}

Since HNO generated by AS may be favored under a reductive environment [33], the GSH/GSSG couple was measured at CT14 and CT18 in SCN tissue homogenates as a reliable measure of the cellular redox state [34]. We found a significant difference in total GSH between CT14 and CT18 $(10.29 \mu \mathrm{m} /(\mathrm{mg} / \mathrm{mL}) \pm 3.99 \mu \mathrm{m} /(\mathrm{mg} / \mathrm{mL})$ vs. $16.42 \mu \mathrm{m} /(\mathrm{mg} / \mathrm{mL}) \pm 6.89 \mu \mathrm{m} /(\mathrm{mg} / \mathrm{mL})$, respectively) $(p<0.05$ paired Student's $t$-test; $t=2.43 ; \mathrm{df}=18 ; n=6)$. When GSH was analyzed, we found no significant differences (CT14: $8.73 \mu \mathrm{m} /(\mathrm{mg} / \mathrm{mL}) \pm 3.30 \mu \mathrm{m} /(\mathrm{mg} / \mathrm{mL})$ vs. CT18: $9.98 \mu \mathrm{m} /(\mathrm{mg} / \mathrm{mL}) \pm 3.91 \mu \mathrm{m} /(\mathrm{mg} / \mathrm{mL}))$. Nevertheless, GSSG was significantly higher at CT18 when compared with CT14 (CT14: $0.13 \mu \mathrm{m} /(\mathrm{mg} / \mathrm{mL}) \pm 0.11 \mu \mathrm{m} /(\mathrm{mg} / \mathrm{mL})$ vs. CT18: $0.58 \mu \mathrm{m} /(\mathrm{mg} / \mathrm{mL}) \pm 0.31 \mu \mathrm{m} /(\mathrm{mg} / \mathrm{mL}))$ $(p<0.01$ paired $t$ test $t=3.99 ; \mathrm{df}=15 ; n=6)$, indicating a more oxidized state at CT18 in the SCN. This was confirmed when analyzing the GSH/GSSG ratio, resulting in significantly lower values for CT18 (CT14: $104.9 \mu \mathrm{m} /(\mathrm{mg} / \mathrm{mL}) \pm 42.38 \mu \mathrm{m} /(\mathrm{mg} / \mathrm{mL})$ vs. CT18: $11.62 \mu \mathrm{m} /(\mathrm{mg} / \mathrm{mL}) \pm 3.37 \mu \mathrm{m} /(\mathrm{mg} / \mathrm{mL}))(p<0.001$ paired $t$-test $t=5.38 ; \mathrm{df}=10 ; n=6)$ (Figure 3). These results allowed us to hypothesize that pharmacological generation of HNO could be favored under a reductive environment at CT14.

\subsection{Effect of NAC and GSH Administration on Light-Induced Phase-Shifts}

To test the effect of changing the redox environment on photic entrainment, we performed a set of experiments that used acute i.c.v. treatment with NAC or GSH, paired with a subsaturant $\mathrm{LP}$. When compared with vehicles, the photically-induced shifts were not affected by NAC, both at CT14 or CT18 (Figure 4A,B). Also, NAC delayed the phase of locomotor rhythm at CT14 in a magnitude that was significantly different from the vehicle (Vehicle Dark: $-23.71 \mathrm{~min} \pm 19.54 \mathrm{~min}$; NAC Dark: $-104 \mathrm{~min} \pm 49.7 \mathrm{~min}$ ) but did not affect light-induced phase-delays (Vehicle LP: $-157.4 \mathrm{~min} \pm 61.22 \mathrm{~min}$; NAC LP: $-85.63 \mathrm{~min} \pm 37.29 \mathrm{~min}$ ) (Two-way ANOVA; LP $p<0.001, \mathrm{~F}=21.17, \mathrm{DFn}=1, \mathrm{DFd}=25$; Drug $p=\mathrm{ns}, \mathrm{F}=0.06$; interaction $p<0.001, \mathrm{~F}=21.17$ ). NAC had no effect over circadian synchronization at CT18 by itself (Vehicle Dark: $-0.33 \mathrm{~min} \pm 9.16 \mathrm{~min}$; NAC Dark: $-12 \mathrm{~min} \pm 30.87 \mathrm{~min}$ ) or with a concomitant light pulse (Vehicle LP: $102.6 \mathrm{~min} \pm 33.83 \mathrm{~min}$; NAC LP: $60 \mathrm{~min} \pm 36.14 \mathrm{~min}$ ) (Two-way ANOVA; LP $p<0.0001, \mathrm{~F}=62.23, \mathrm{DFn}=1$, $\mathrm{DFd}=27$; Drug $p<0.05, \mathrm{~F}=5.99$; interaction $p=\mathrm{ns}, \mathrm{F}=1.95)$. A similar result was found for GSH, which induced phase-delays at CT14 (Vehicle Dark: $-12.17 \mathrm{~min} \pm 6.67 \mathrm{~min}$; GSH Dark: $-70.8 \mathrm{~min} \pm 23.38 \mathrm{~min}$ ) and did not change the effect of light pulses (Vehicle LP: $-81.29 \mathrm{~min} \pm 23.94 \mathrm{~min}$; GSH LP: $-55 \mathrm{~min} \pm 15.186 \mathrm{~min}$ ) (Two-way ANOVA; LP $p<0.01, \mathrm{~F}=30.47, \mathrm{DFn}=1, \mathrm{DFd}=20$; Drug $p<0.05, \mathrm{~F}=12.01$; interaction $p<0.0001$, $\mathrm{F}=30.47$ ) (Figure $4 \mathrm{C}$ ). Also, GSH had no effect at CT18 either by itself (Vehicle Dark: 
$6.45 \mathrm{~min} \pm 26.77 \mathrm{~min}$; GSH Dark: $-7 \mathrm{~min} \pm 13.96 \mathrm{~min}$ ) or interacting with light (Vehicle LP: $82.72 \mathrm{~min} \pm 62.37 \mathrm{~min}$; GSH LP: $63.43 \mathrm{~min} \pm 34.64 \mathrm{~min}$ ) (Two-way ANOVA; LP $p<0.0001, \mathrm{~F}=25.42, \mathrm{DFn}=1, \mathrm{DFd}=40$; Drug $p=\mathrm{ns}, \mathrm{F}=1.27$; interaction $p=\mathrm{ns}, \mathrm{F}=1.27)$ (Figure 4D). These results show that antioxidants NAC and GSH are able to modulate the circadian phase at CT14.
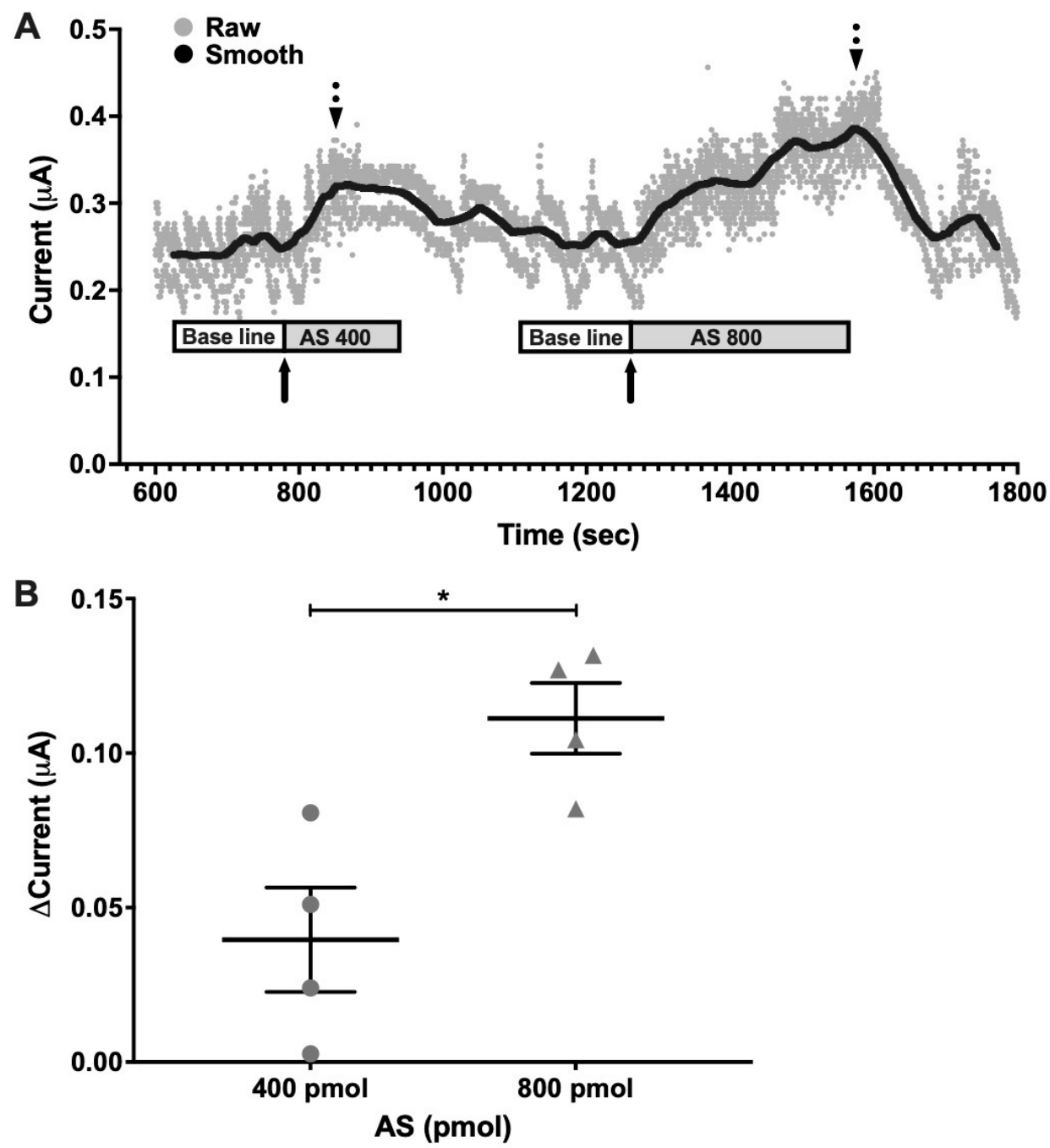

Figure 2. Electrochemical detection of nitroxyl (HNO) in vivo at the SCN. HNO generated in vivo by decomposition of Angeli's Salt (AS) donor detected by time-resolved electrochemical quantification at the SCN in the pmolar range. (A) Representative graph of individual raw (Raw) and filtered (Smooth) data series using a moving average with a step of 300 samples to obtain $1 \mathrm{~min}$-bin. After at least $2 \mathrm{~min}$ of baseline current register (white boxes), AS was delivered i.c.v from a $100 \mu \mathrm{M}$ solution at $1.5 \mu \mathrm{L} / \mathrm{min}$ rate (grey boxes). Filled arrows indicate the time of injection with $400 \mathrm{pmol}$ and $800 \mathrm{pmol}$ of AS which corresponds with the registration of the baseline current, while dotted arrows indicate maximum current, which correlates to maximum HNO production. (B) Delta current values, calculated as the difference between maximum post-injection and basal prior-injection current values, for $400 \mathrm{pmol}$ and $800 \mathrm{pmol}$ AS. $n=4 ;{ }^{*} p<0.05$, paired $t$-test. 


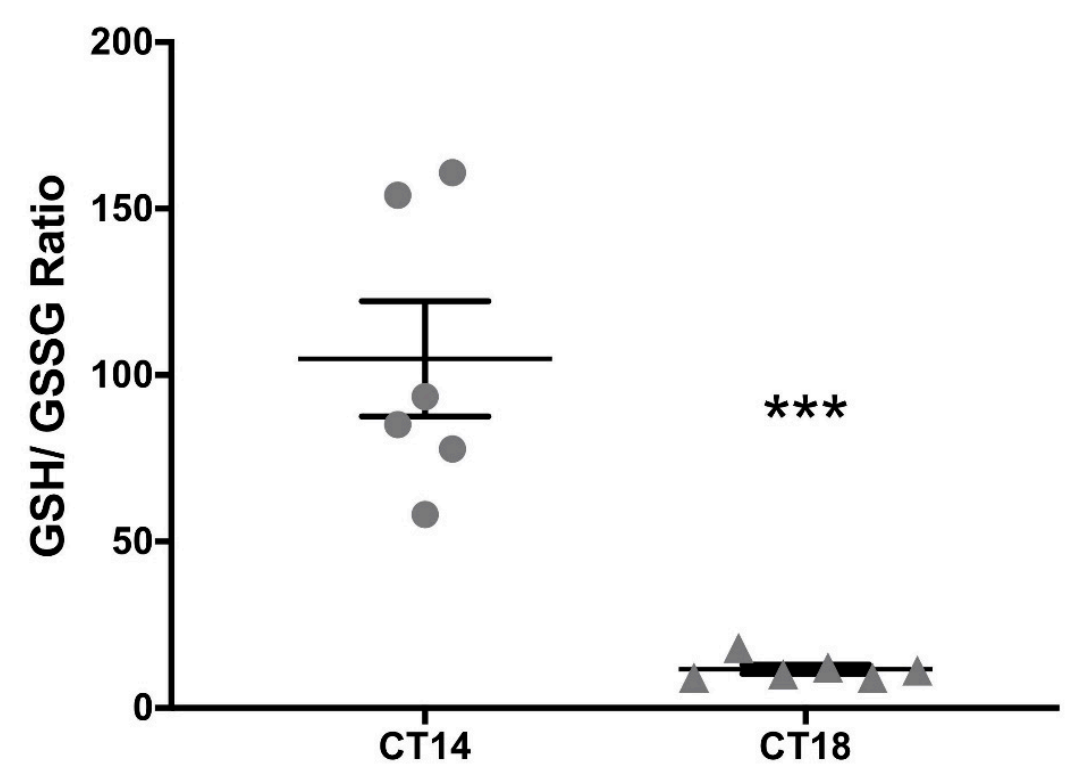

Figure 3. Glutathione couple measurement in the SCN at subjective night. The redox state was assessed as the GSH/GSSG ratio. Brains were collected at CT14 and CT18 and samples were frozen at $-80^{\circ} \mathrm{C}$. SCNs from 2-3 individuals were pooled for measuring reduced (GSH) and total glutathione, inferring oxidized glutathione (GSSG) values using the equation GSSG $=($ total glutathione-GSH) $/ 2$. The rate relation was also calculated as GSH/GSSG, thus indicating a more oxidized environment when the relation was lower. Significantly lower values for CT18 were found, indicating a more oxidized environment at late subjective night (CT14: $104.9 \mu \mathrm{m} /(\mathrm{mg} / \mathrm{mL}) \pm 42.38 \mu \mathrm{m} /(\mathrm{mg} / \mathrm{mL})$ vs. CT18: $11.62 \mu \mathrm{m} /(\mathrm{mg} / \mathrm{mL}) \pm 3.37 \mu \mathrm{m} /(\mathrm{mg} / \mathrm{mL}))(* * *<0.001$ paired $t$-test; $t=5.38 ; \mathrm{df}=10 ; n=6)$.

CT 14

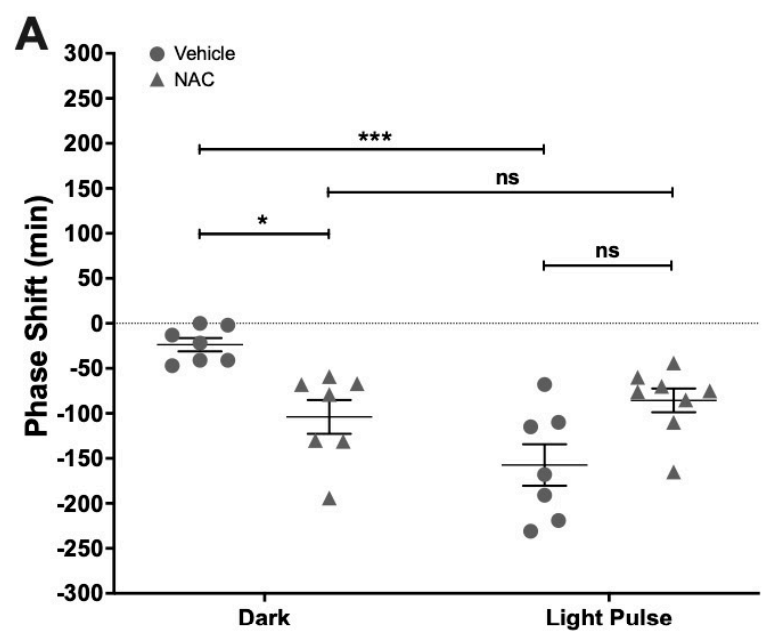

CT 18

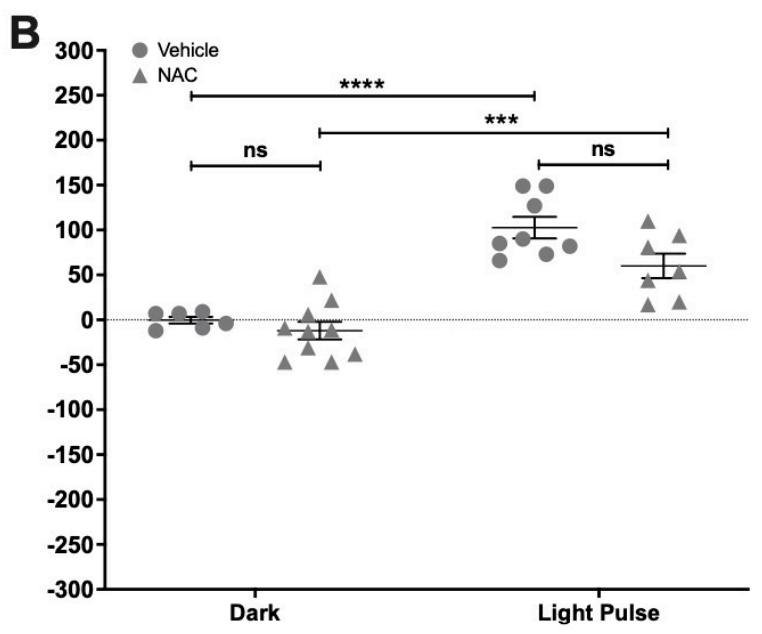

Figure 4. Cont. 

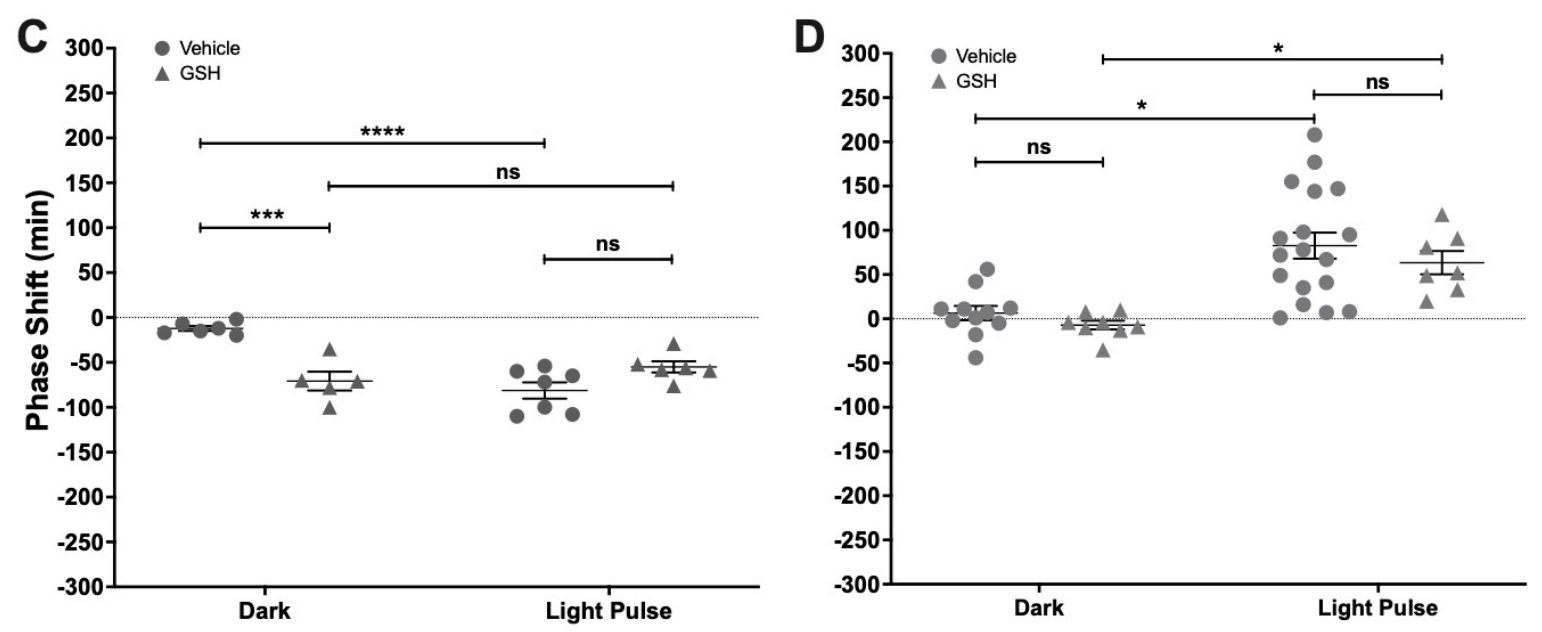

Figure 4. Effect of antioxidants N-acetylcysteine (NAC) and glutathione (GSH) on circadian phase changes. Groups of hamsters in constant darkness conditions were treated with an i.c.v injection of either NAC $(2 \mu \mathrm{L}, 100 \mu \mathrm{M}$, or vehicle) $(\mathbf{A}, \mathbf{B})$ or GSH $(1 \mu \mathrm{L}, 100 \mu \mathrm{M})(\mathbf{C}, \mathbf{D}), 5 \mathrm{~min}$ before a subsaturant light pulse (10 min, 50 lux) delivered at CT14 or CT18. Controls for photic response (Dark) received only pharmacological treatment without light stimuli. Phase changes are shown as mean \pm SEM. Two-way ANOVA, followed by Tukey's multiple comparisons test, ns $=$ not significant; ${ }^{*} p<0.05$; ${ }^{* * *} p<0.001$; ${ }^{* * * *} p<0.0001$; for NAC experiment at CT14: vehicle Dark $n=7$, vehicle LP $n=8$, NAC Dark $n=7$, NAC LP $n=8$; at CT18: vehicle Dark $n=6$, vehicle LP $n=8$, NAC Dark $n=10$, NAC LP $n=7$. For GSH experiment at CT14: vehicle Dark $n=6$, vehicle LP $n=7$, GSH Dark $n=5$, GSH LP $n=6$; at CT18: vehicle Dark $n=11$, vehicle LP $n=17$, GSH Dark $n=8$, GSH LP $n=7)$.

\section{Discussion}

Evidence pointing to $\mathrm{NO} \bullet$ as a diffusible, intra and extracellular messenger participating in the photic transduction of circadian phase-advances is based on: (1) the increased activity in the nNOs/sGC/GMP/PKGII pathway after a light-pulse at CT18 [7,35-37]; (2) the indirect pharmacological reduction of phase-advances at CT18 by nNOS [14,15,17], sGC, and PKGII inhibition [35]; (3) scavenging of extracellular NO• [18]; and (4) enhancement of photic-advances by NO• donors as SNAP [14] and N-nitrosomelatonin [15]. Taken together, the current evidence indicates that a substantial increase in intra and extracellular NO• by its light-induced synthesis at the SCN should be expected at CT18 for phase-advances, as compared with phase-delays.

Here we assessed the role of $\mathrm{HNO}$, a redox form of $\mathrm{NO} \bullet$, in its ability to modulate photic entrainment in the hamster SCN. This compound had two pharmacological effects: it generated phase-delays when delivered alone, and potentiated photic phase-advances. $\mathrm{HNO}$ was electrochemically measured in a dose-dependent relationship in the hamster SCN after delivering the AS donor, verifying its ability to increase $\mathrm{HNO}$ in vivo. The measurement of the GSH/GSSG ratio estimates SCN, GSH, and GSSG concentrations in a 1-10 $\mathrm{mM}$ range [38]. We found a reductive environment at CT14, which may favor the action of the HNO donor AS to generate phase-delays. Rate constants point that HNO oxidation is rather specific for thiols as reductants, while minor for nitrogenous species such as amines, indoles, and purines [29]. HNO oxidation should be determined by the availability of major cellular free thiols, such as glutathione, under reductive environment [20], while an oxidative environment would induce oxidation to $\mathrm{NO} \bullet$ and auto-dimerization and/or reaction with oxygen to form nitrous oxide, nitrate, nitrite [28,39], and peroxynitrite [40]. Moreover, physiological detection of $\mathrm{NO} \bullet$ by nNOS synthesis is dependent on oxidation of $\mathrm{HNO}$ (a primary product of $\mathrm{nNOS}$ ) to $\mathrm{NO \bullet}$, catalyzed by the increase in superoxide dismutase activity under an oxidative environment [41], although this finding I challenged by [42]. Also, HNO can directly increase sGC enzymatic activity per se as found in purified lung extracts [43]. 
Biological actions of $\mathrm{HNO}$ are largely explained due to its reactivity to free thiols (i.e., GSH) and cysteine residues. Most studies assessed its effects in the cardiovascular system, associated with the oxidation of free cysteine thiol residues [30], as well as with sarcoplasmic RyRs, increasing calcium release [44]. A few studies were done in the central nervous system, comparing the effects of AS with the NO• donor diethylammonium (Z)-1-(N,N-diethylamino)diazen-1-ium-1,2-diolate (DEA/NO) in the hamster retina [45]. Compared with DEA/NO, AS generates similar inhibition of nNOS activity and L-citrulline transport and reduction of GSH and protein S-nitrosation, but less cGMP induction. High (400 nM), chronic (7 days) AS, administered intranigrostriatally as a model of neurodegeneration, induces GSH depletion and dopaminergic neuronal loss [46]. The relatively high GSH concentrations we measured at CT14 (1-10 mM) is not expected to change after reacting with low $\mathrm{HNO}$ concentration generated by 100 pmol AS in the SCN. At low HNO concentration, reaction with thiol proteins to form S-nitrosation is feasible without altering free thiol concentration [28], via thiol condensation with the one-electron oxidation of NO•, nitrous acid [20,23], or via dinitrosyl iron complexes [47]. In addition, to separate both pathways based only on the global redox state (favoring the action of HNO at CT14) is a simplification, since in fact S-nitrosation should be favored under an oxidative environment; indeed, other factors such as target availability must be considered.

Although the SCN is very robust in keeping the circadian phase, here we report that both antioxidants GSH and NAC generate phase-delays of locomotor rhythms at CT14. In pathologies involving oxidative stress, NAC has several possible mechanisms of action as a therapeutic antioxidant: it can (1) act as a free-radical (RNS and ROS) and reactive electrophile scavenger; (2) increase the synthesis of GSH by its rapid deacetylation in the cell to form cysteine-cystine; and (3) reduce disulfide bonds [48]. We found similar circadian effects of GSH and NAC. In other models, NAC has been reported to deliver cysteine-cystine increasing GSH in the brain [49] for long term treatment as needed in neurodegeneration [50]; however, our results suggest a faster activity that should happen within a 3-h time-window in order to induce circadian resetting through changes in per1-2 activity. In addition, it was shown that the inhibition of the activity of nNOS/cGC/PKGII input pathway components $[36,37]$ delayed the circadian phase, so we could hypothesize that the phase-delays induced by GSH or NAC could be generated by a redox-dependent inhibition of the same pathway, as occurs with NOS activity and L-arginine uptake by AS treatment in the retina [45]. While Wang et al. [5] evidenced the effect of GSH on resting electrical activity in SCN slices, few circadian studies were done with NAC, which had inconsistent effects [51,52].

Measuring glutathione couple (GSH/GSSG ratio) in the SCN indicated a higher reductive environment at CT14, when compared with CT18. A recent study also showed high GSH concentration in rat brain tissue during the day [53]. In rat SCN organotypic slices, a relatively oxidized state at CT14 was reported by measuring glutathiolation [5] (i.e., the addition of glutathione to protein thiols via oxidative intermediates GSSG and/or GSNO, [54]), and dehydroascorbic/ascorbic acid ratio. The methods used in this study differ from the ones reported here, since the authors sacrificed rats and recorded redox states in sliced brain. Our results do agree with others in which the redox state was derived from glutathiolation state at CT6 vs. CT14 in SCN homogenates [55]. Experiments done by Wang et al. [5] were the first to assess a circadian rhythm in SCN redox state, coupled with the rhythm in membrane excitability by post-translational redox regulation of both leak and A-type $\mathrm{K}^{+}$channels.

Several post-translational inputs from metabolic and redox pathways regulate the activity and stability of core clock proteins, such as heme binding on REV-ERBa and REV-ERBb, regulating BMAL1 stability and repression [10], or the interplay between zinc binding and disulfide bond formation, stabilizing the PER2:CRY1 heterodimer [56]. Increasing the oxidative environment by acute treatment with hydrogen peroxide was shown to destabilize PER2, altering the phase and amplitude of PER2: LUC bioluminescence rhythms in fibroblasts [57]. Indeed, a circadian oscillation of hydrogen peroxide determines a redox 
oscillation of CLOCK through Cys195 thiol oxidation, which promotes its interaction with BMAL1, enhances transcriptional activity of clock genes, and sets the molecular oscillator period in vitro [58].

To conclude, our results support the idea that the redox state could modulate SCN clock messengers for entrainment pathways downstream of NO•, as well as work as an input for circadian phase determination. Delivering nitroxyl by AS at the SCN exposes this redox-dependent form of NO• as a noncanonical messenger in the control of the circadian phase. The putative targets for nitroxyl in the SCN-as well as the redox factors affecting the circadian clock-remain to be established, whereas S-nitrosation of ryanodine receptors and/or clock proteins emerge as strong candidates for involvement in this modulation.

\section{Materials and Methods}

\subsection{Pharmacological Modulation of Photic Entrainment}

\subsubsection{Animals and Housing}

Male, 3-4-month-old Syrian hamsters (Mesocricetus auratus) (Laboratorio Azul Diagnóstico, Azul, Buenos Aires, Argentina) were used. Animals were put in group cages of 5 individuals and acclimatized in stock rooms for at least two weeks under standardized conditions (14 h light: $10 \mathrm{~h}$ dark (LD 14:10), $\left.20( \pm 2){ }^{\circ} \mathrm{C}\right)$, before entering the experimental protocols. Light was set as 200 lux of white "cool" light at cage bedding level. Lights-OFF was defined as zeitgeber time 12 (ZT12). Animals received rodent diet chow (ACA Cooperación, San Nicolás, Buenos Aires, Argentina) and tap water ad-libitum, with wood chip bedding renewal every 4 days.

\subsubsection{Drugs}

Reduced glutathione (GSH) and N-acetyl-L-cysteine (NAC) (Sigma Aldrich, St. Louis, $\mathrm{MO}, \mathrm{USA})$ were diluted from stock solutions. Sodium trioxodinitrate $\left(\mathrm{Na}_{2}\left[\mathrm{~N}_{2} \mathrm{O}_{3}\right]\right.$ Angeli's salt, AS) was synthesized at the laboratory of Fabio Doctorovich (INQUIMAE-CONICET, Universidad de Buenos Aires) as described in [59]. Fresh drug dilutions were used just before administration.

\subsubsection{Surgeries and Intracerebroventricular Microinjections}

For intracerebroventricular (i.c.v.) administrations, a 22-gauge steel guide cannula (Plastic Products, Roanoke, VA, USA) was implanted under isoflurane ( $5 \%$ in oxygen for induction, $2 \%$ for maintenance, $200 \mathrm{~mL} / \mathrm{min}$ ) aimed at $1.0 \mathrm{~mm}$ above the target site between the bilateral SCN (stereotaxic coordinates: anterior / posterior $=+0.6$, medial $/$ lateral $=0.0$, dorsal/ventral $=-8.0 \mathrm{~mm}$ from bregma). After surgery, hamsters were kept under standard 14:10 LD cycles to recover for 7 to 10 days before being transferred to constant darkness (DD) for the duration of the experiment. All microinjections were performed under darkness in agreement with DD conditions (i.e., CT14 and CT18) with the use of a dim red light to aim and gentle restraint of the animals for about 1 min to deliver $1 \mu \mathrm{L}$ using a Hamilton microsyringe (Reno, NV, USA). All animal procedures were performed in accordance with the Institutional Animal Care and Use Committee of the Universidad Nacional de Quilmes.

\subsubsection{Behavioral Experiments}

The locomotor activity rhythm was obtained to assess the SCN clock output response under typical light-pulse experiments (i.e., nonparametric entrainment paradigm) (Figure 1, panels C-E) (see Statistical and Chronobiological Analyses, below). Wheel running activity was recorded using a data acquisition system designed in our lab. Hamsters were transferred into light-isolated closets with individual cages equipped with a running wheel to obtain time series of wheel revolutions accumulated, recorded each 5 min to a hard drive. For light-pulse (LP) experiments, the design includes two treatments as factors in an unpaired design: light induction (LP, or dark), and drug (drug, or vehicle VEH). The variable analyzed was the phase-shift, which was assessed in individual actograms (see Statistical and Chronobiological Analyses). Activity onset was eye-fitted in actograms 
as a typical circadian phase marker, defined as circadian time 12 (CT12). The behavioral protocols were as follows: hamsters were transferred from LD 14:10 to constant darkness (DD) for at least 15 days to obtain a stable free-running period under DD conditions. Then, a subsaturant LP (50 lux, $10 \mathrm{~min}$ ) was delivered at two experimental CTs: CT14, to induce phase-delays, and at CT18, to induce advances. Drug delivery was set $5 \mathrm{~min}$ before the LP, in subgroups of hamsters that were separated to receive an i.c.v. injection of: AS (1 $\mu \mathrm{L}$, $100 \mu \mathrm{M})$, GSH $(1 \mu \mathrm{L}, 100 \mu \mathrm{M})$, or NAC $(2 \mu \mathrm{L}, 100 \mu \mathrm{M})$. For the duration of the protocols, animals received food and tap water ad libitum, and cages were cleaned and bedding was replaced every 7 days.

\subsubsection{Electrochemical Detection of Nitroxyl In Vivo at the SCN}

Nitroxyl generated in vivo by Angeli's Salt donor was detected at the SCN in the pmolar range by time-resolved electrochemical quantification [60]. To this end, hamsters under LD cycles were implanted under darkness at ZT14 with the sensing electrode coupled to an internal cannula at SCN stereotaxic coordinates (see above in Surgeries and Intracerebroventricular Microinjections) for acute infusions (1.5 $\mu \mathrm{L} / \mathrm{min})$. Current intensity generated was monitored in real-time and registered each $0.2 \mathrm{~s}$ during the course of the experiment. Once steady baseline recording was set under vehicle infusion, paired drug-treatments were tested in each subject (using sequential microinjections of 2, 400, and 800 pmol; see Figure 2) with vehicle wash-out prior to all drug administrations (200 pmol dosing did not generate evident changes in the signal, thus it was not included in the analyses). Individual raw data series were filtered for high-frequency noise using a moving average with a step of 300 samples to obtain 1 min-bin series for the following calculations: two time-windows of $3 \mathrm{~min}$ data were averaged, one to set baseline values, taking 3 data points prior to drug injection, and the other post-drug infusion to set maximum, taking 3 data points around the higher recorded value. Maximum and baseline were subtracted to calculate the change in the electrical current.

\subsubsection{Measurement of the Redox Pair GSH/GSSG at the SCN}

To study the redox state of the SCN at subjective night, we focused on the pair GSH-GSSG, the main redox couple in the cell [38]. Hamsters were kept under DD conditions and groups were set at CT14 or CT18. Individuals were euthanized by decapitation and their brains frozen in liquid nitrogen. For determination of GSH-GSSG levels, a commercial kit (Fluorometric-Green, Abcam, Cambridge, UK) with maximal detection of $10 \mu \mathrm{M}$ was used following the provider's instructions. Briefly, a 1-mm thick coronal slice containing the SCN was sectioned from the brain. A tissue sample was extracted just above the chiasm at the suprachiasmatic region. Samples corresponding to $2-3$ brains were pooled (i.e., $n=1$ corresponds to $2-3$ pooled brains of the same experimental group) for each determination of GSH and total glutathione (GSH + GSSG) values, inferring GSSG values using the equation GSSG = (total glutathione - GSH)/2. Values obtained were relativized in proportion to the total amount of protein, measured by Bradford Assay. Measurements were performed using a Cytation 5 Imaging reader (Biotek Instruments, Winuschi, VT, USA), at Ex $/ E m=490 / 520 \mathrm{~nm}$. The GSH/GSSG ratio was calculated, indicating a more oxidized environment when the value is lower.

\subsubsection{Statistical and Chronobiological Analyses}

Individuals were randomly assigned for all the experiments into their corresponding groups. For the GSH/GSSG ratio experiment, each experimental sample is composed of a pool of SCN tissue obtained from 2-3 hamster brains. Normal distributions were tested with Shapiro-Wilk normality test and then parametric analyses were performed ( $t$-test, one-way and two-way ANOVA, as indicated in the text) and post-hoc tests (Bonferroni and Tukey's multiple comparison tests) were applied when indicated. Results are presented as mean \pm SEM of experimental datasets. Statistical analyses were performed with GraphPad Prism 8 (GraphPad Software, La Jolla, CA, USA) software. $p$-values lower than 0.05 were 
considered to reach statistical significance. Time-series of wheel running activity were represented in actograms plotted at modulo Tau (i.e., using the free running period of the corresponding individual) to analyze the phase of locomotor rhythms (panels C-E in the Figure 1 show actograms of representative rhythms). An eye-fitted line set at the onsets of locomotor activity were obtained in the actograms as a typical marker of the circadian phase, to obtain the times for CT12 and CT18. Phase-shifts were calculated by fitting a line through activity onsets 15 days prior to, and between 5 and 15 days after, the day of treatment; the time difference between the extrapolation of these two lines on the day of treatment (i.e., a phase-shift) was calculated. Chronobiological analyses were done using an integrated package for chronobiology, El Temps (Antoni Díez Noguera, Universitat de Barcelona, Spain).

Author Contributions: S.A.P. and F.M.B. performed all the experiments, analyzed the results, and edited the manuscript; L.L.T. performed glutathione measurement and contributed to the manuscript edition, S.Á.S. and F.D. designed the device, contributed to the electrochemical measurement of nitroxyl, and synthesized Angeli's salt; D.A.G. and J.J.C. designed the experiments, supervised the results, and generated and revised the final version of the manuscript. All authors have read and agreed to the published version of the manuscript.

Funding: The author(s) disclosed receipt of the following financial support for the research, authorship, and/or publication of this article: Materials and reagents used for this work were funded by grants from the Ministerio de Ciencia, Tecnología e Innovación, Agencia Nacional de Promoción de la Investigación, el Desarrollo Tecnológico y la Innovación [PICT 2099-2014], Argentina; and the Universidad Nacional de Quilmes [PUNQ 1310/19], Argentina. S.A.P., S.Á.S., F.D., D.A.G., and J.J.C. are researchers from Consejo Nacional de Investigaciones Científicas y Técnicas (CONICET), Argentina.

Institutional Review Board Statement: The study was conducted according to the guidelines of the Declaration of Helsinki and approved by the Institutional Review Board of Universidad Nacional de Quilmes.

Data Availability Statement: The datasets used and/or analyzed during the current study are available from the corresponding author on reasonable request.

Acknowledgments: The authors are thankful for institutional support from the Ministerio de Ciencia, Tecnología e Innovación, the Consejo Nacional de Investigaciones Científicas y Técnicas, and the Universidad Nacional de Quilmes.

Conflicts of Interest: The authors declare no conflict of interest.

Sample Availability: Samples of the compounds are available from the corresponding author on reasonable request.

\section{References}

1. Schibler, U.; Sassone-Corsi, P. A Web of Circadian Pacemakers. Cell 2002, 111, 919-922. [CrossRef]

2. Hegazi, S.; Lowden, C.; Garcia, J.R.; Cheng, A.H.; Obrietan, K.; Levine, J.D.; Cheng, H.-Y.M. A Symphony of Signals: Intercellular and Intracellular Signaling Mechanisms Underlying Circadian Timekeeping in Mice and Flies. Int. J. Mol. Sci. 2019, 20, 2363. [CrossRef]

3. Asher, G.; Gatfield, D.; Stratmann, M.; Reinke, H.; Dibner, C.; Kreppel, F.; Mostoslavsky, R.; Alt, F.W.; Schibler, U. SIRT1 Regulates Circadian Clock Gene Expression through PER2 Deacetylation. Cell 2008, 134, 317-328. [CrossRef] [PubMed]

4. Hirano, A.; Braas, D.; Fu, Y.-H.; Ptáček, L.J. FAD Regulates CRYPTOCHROME Protein Stability and Circadian Clock in Mice. Cell Rep. 2017, 19, 255-266. [CrossRef] [PubMed]

5. Wang, T.A.; Yu, Y.V.; Govindaiah, G.; Ye, X.; Artinian, L.; Coleman, T.P.; Sweedler, J.V.; Cox, C.L.; Gillette, M.U. Circadian Rhythm of Redox State Regulates Excitability in Suprachiasmatic Nucleus Neurons. Science 2012, 337, 839-842. [CrossRef] [PubMed]

6. Golombek, D.A.; Rosenstein, R.E. Physiology of Circadian Entrainment. Physiol. Rev. 2010, 90, 1063-1102. [CrossRef] [PubMed]

7. Agostino, P.V.; Ferreyra, G.A.; Murad, A.D.; Watanabe, Y.; Golombek, D.A. Diurnal, circadian and photic regulation of calcium/calmodulin-dependent kinase II and neuronal nitric oxide synthase in the hamster suprachiasmatic nuclei. Neurochem. Int. 2004, 44, 617-625. [CrossRef] [PubMed]

8. Golombek, D.A.; Agostino, P.V.; Plano, S.A.; Ferreyra, G.A. Signaling in the mammalian circadian clock: The NO/cGMP pathway. Neurochem. Int. 2004, 45, 929-936. [CrossRef]

9. Plano, S.A.; Alessandro, M.S.; Trebucq, L.L.; Endo, S.; Golombek, D.A.; Chiesa, J.J. Role of G-Substrate in the NO/cGMP/PKG Signal Transduction Pathway for Photic Entrainment of the Hamster Circadian Clock. ASN Neuro 2021, 13, 1759091420984920. [CrossRef] 
10. Ding, J.M.; Buchanan, G.F.; Tischkau, S.A.; Chen, D.; Kuriashkina, L.; Faiman, L.E.; Alster, J.M.; McPherson, P.S.; Campbell, K.P.; Gillette, M.U. A neuronal ryanodine receptor mediates light-induced phase delays of the circadian clock. Nature 1998, 394, 381-384. [CrossRef]

11. Gau, D.; Lemberger, T.; von Gall, C.; Kretz, O.; Le Minh, N.; Gass, P.; Schmid, W.; Schibler, U.; Korf, H.W.; Schütz, G. Phosphorylation of CREB Ser142 Regulates Light-Induced Phase Shifts of the Circadian Clock. Neuron 2002, 34, 245-253. [CrossRef]

12. Ding, J.M.; Faiman, L.E.; Hurst, W.J.; Kuriashkina, L.R.; Gillette, M.U. Resetting the Biological Clock: Mediation of Nocturnal CREB Phosphorylation via Light, Glutamate, and Nitric Oxide. J. Neurosci. 1997, 17, 667-675. [CrossRef]

13. Tischkau, S.A.; Gallman, E.A.; Buchanan, G.F.; Gillette, M.U. Differential cAMP Gating of Glutamatergic Signaling Regulates Long-Term State Changes in the Suprachiasmatic Circadian Clock. J. Neurosci. 2000, 20, 7830-7837. [CrossRef]

14. Melo, L.; Golombek, D.A.; Ralph, M.R. Regulation of circadian photic responses by nitric oxide. J. Biol. Rhythm. 1997, 12, 319-326. [CrossRef] [PubMed]

15. Baidanoff, F.M.; Plano, S.A.; Doctorovich, F.; Suárez, S.A.; Golombek, D.A.; Chiesa, J.J. N-nitrosomelatonin enhances photic synchronization of mammalian circadian rhythms. J. Neurochem. 2014, 129, 60-71. [CrossRef] [PubMed]

16. Gonzalez, D.R.; Fernández, I.C.; Ordenes, P.P.; Treuer, A.V.; Eller, G.; Boric, M.P. Differential role of S-nitrosylation and the NO-cGMP-PKG pathway in cardiac contractility. Nitric Oxide 2008, 18, 157-167. [CrossRef]

17. Watanabe, A.; Ono, M.; Shibata, S.; Watanabe, S. Effect of a nitric oxide synthase inhibitor, N-nitro-l-arginine methylester, on lightinduced phase delay of circadian rhythm of wheel-running activity in golden hamsters. Neurosci. Lett. 1995, 192, 25-28. [CrossRef]

18. Plano, S.A.; Golombek, D.A.; Chiesa, J.J. Circadian entrainment to light-dark cycles involves extracellular nitric oxide communication within the suprachiasmatic nuclei. Eur. J. Neurosci. 2010, 31, 876-882. [CrossRef] [PubMed]

19. Chiesa, J.J.; Baidanoff, F.M.; Golombek, D.A. Don't just say no: Differential pathways and pharmacological responses to diverse nitric oxide donors. Biochem. Pharmacol. 2018, 156, 1-9. [CrossRef] [PubMed]

20. Smith, B.C.; Marletta, M.A. Mechanisms of S-nitrosothiol formation and selectivity in nitric oxide signaling. Curr. Opin. Chem. Biol. 2012, 16, 498-506. [CrossRef] [PubMed]

21. Martínez-Ruiz, A.; Araújo, I.M.; Izquierdo-Álvarez, A.; Hernansanz-Agustín, P.; Lamas, S.; Serrador, J.M. Specificity in SNitrosylation: A Short-Range Mechanism for NO Signaling? Antioxid. Redox Signal. 2013, 19, 1220-1235. [CrossRef]

22. Hughes, M.N. Relationships between nitric oxide, nitroxyl ion, nitrosonium cation and peroxynitrite. Biochim. Biophys. Acta Bioenerg. 1999, 1411, 263-272. [CrossRef]

23. Turell, L.; Zeida, A.; Trujillo, M. Mechanisms and consequences of protein cysteine oxidation: The role of the initial short-lived intermediates. Essays Biochem. 2020, 64, 55-66. [CrossRef] [PubMed]

24. Arnelle, D.R.; Stamler, J.S. NO+, NO, and NO- Donation by S-Nitrosothiols: Implications for Regulation of Physiological Functions by S-Nitrosylation and Acceleration of Disulfide Formation. Arch. Biochem. Biophys. 1995, 318, 279-285. [CrossRef] [PubMed]

25. Stamler, J.S.; Meissner, G. Physiology of Nitric Oxide in Skeletal Muscle. Physiol. Rev. 2001, 81, 209-237. [CrossRef] [PubMed]

26. Cammack, R.; Shergill, J.K.; Inalsingh, V.A.; Hughes, M.N. Applications of electron paramagnetic resonance spectroscopy to study interactions of iron proteins in cells with nitric oxide. Spectrochim. Acta Part A Mol. Biomol. Spectrosc. 1998, 54, 2393-2402. [CrossRef]

27. Parissis, J.; Bistola, V.; Ikonomidis, I.; Triposkiadis, F. Nitroxyl donors for acute heart failure: Promising newcomers. Eur. J. Heart Fail. 2017, 19, 1333-1334. [CrossRef]

28. Fukuto, J.M. A recent history of nitroxyl chemistry, pharmacology and therapeutic potential. Br. J. Pharmacol. 2019, 176, 135-146. [CrossRef]

29. Paolocci, N.; Saavedra, W.F.; Miranda, K.M.; Martignani, C.; Isoda, T.; Hare, J.M.; Espey, M.G.; Fukuto, J.M.; Feelisch, M.; Wink, D.A.; et al. Nitroxyl anion exerts redox-sensitive positive cardiac inotropy in vivo by calcitonin gene-related peptide signaling. Proc. Natl. Acad. Sci. USA 2001, 98, 10463-10468. [CrossRef]

30. Choe, C.-U.; Lewerenz, J.; Gerloff, C.; Magnus, T.; Donzelli, S. Nitroxyl in the Central Nervous System. Antioxid. Redox Signal. 2011, 14, 1699-1711. [CrossRef]

31. Dutton, A.S.; Fukuto, J.M.; Houk, K.N. Mechanisms of HNO and NO Production from Angeli's Salt: Density Functional and CBS-QB3 Theory Predictions. J. Am. Chem. Soc. 2004, 126, 3795-3800. [CrossRef]

32. Amatore, C.; Arbault, S.; Ducrocq, C.; Hu, S.; Tapsoba, I. Angeli's Salt (Na2N2O3) is a Precursor of HNO and NO: A Voltammetric Study of the Reactive Intermediates Released by Angeli's Salt Decomposition. ChemMedChem 2007, 2, 898-903. [CrossRef]

33. Suarez, S.A.; Vargas, P.; Doctorovich, F.A. Updating NO•/HNO interconversion under physiological conditions: A biological implication overview. J. Inorg. Biochem. 2021, 216, 111333. [CrossRef]

34. Giustarini, D.; Colombo, G.; Garavaglia, M.L.; Astori, E.; Portinaro, N.M.; Reggiani, F.; Badalamenti, S.; Aloisi, A.M.; Santucci, A.; Rossi, R.; et al. Assessment of glutathione/glutathione disulphide ratio and S-glutathionylated proteins in human blood, solid tissues, and cultured cells. Free. Radic. Biol. Med. 2017, 112, 360-375. [CrossRef] [PubMed]

35. Ferreyra, G.A.; Golombek, D.A. Rhythmicity of the cGMP-related signal transduction pathway in the mammalian circadian system. Am. J. Physiol. Regul. Integr. Comp. Physiol. 2001, 280, R1348-R1355. [CrossRef]

36. Tischkau, S.A.; Mitchell, J.W.; Pace, L.A.; Barnes, J.W.; Barnes, J.A.; Gillette, M.U. Protein Kinase G Type II Is Required for Night-to-Day Progression of the Mammalian Circadian Clock. Neuron 2004, 43, 539-549. [CrossRef] 
37. Tischkau, S.A.; Weber, E.T.; Abbott, S.M.; Mitchell, J.W.; Gillette, M.U. Circadian Clock-Controlled Regulation of cGMP-Protein Kinase G in the Nocturnal Domain. J. Neurosci. 2003, 23, 7543-7550. [CrossRef] [PubMed]

38. Schafer, F.Q.; Buettner, G.R. Redox environment of the cell as viewed through the redox state of the glutathione disulfide/glutathione couple. Free. Radic. Biol. Med. 2001, 30, 1191-1212. [CrossRef]

39. Miranda, K.M.; Paolocci, N.; Katori, T.; Thomas, D.D.; Ford, E.; Bartberger, M.D.; Espey, M.G.; Kass, D.A.; Feelisch, M.; Fukuto, J.M.; et al. A biochemical rationale for the discrete behavior of nitroxyl and nitric oxide in the cardiovascular system. Proc. Natl. Acad. Sci. USA 2003, 100, 9196-9201. [CrossRef] [PubMed]

40. Smulik, R.; Dębski, D.; Zielonka, J.; Michałowski, B.; Adamus, J.; Marcinek, A.; Kalyanaraman, B.; Sikora, A. Nitroxyl (HNO) Reacts with Molecular Oxygen and Forms Peroxynitrite at Physiological pH: Biological implications. J. Biol. Chem. 2014, 289, 35570-35581. [CrossRef]

41. Schmidt, H.H.H.W.; Hofmann, H.; Schindler, U.; Shutenko, Z.S.; Cunningham, D.D.; Feelisch, M. No ·NO from NO synthase. Proc. Natl. Acad. Sci. USA 1996, 93, 14492-14497. [CrossRef]

42. Xia, Y.; Zweier, J.L. Direct measurement of nitric oxide generation from nitric oxide synthase. Proc. Natl. Acad. Sci. USA 1997, 94, 12705-12710. [CrossRef]

43. Miller, T.W.; Cherney, M.M.; Lee, A.J.; Francoleon, N.E.; Farmer, P.J.; King, S.B.; Hobbs, A.J.; Miranda, K.M.; Burstyn, J.N.; Fukuto, J.M. The Effects of Nitroxyl (HNO) on Soluble Guanylate Cyclase Activity: INTERACTIONS AT FERROUS HEME AND CYSTEINE THIOLS. J. Biol. Chem. 2009, 284, 21788-21796. [CrossRef]

44. Cheong, E.; Tumbev, V.; Abramson, J.; Salama, G.; Stoyanovsky, D.A. Nitroxyl triggers Ca2+ release from skeletal and cardiac sarcoplasmic reticulum by oxidizing ryanodine receptors. Cell Calcium 2005, 37, 87-96. [CrossRef]

45. Sáenz, D.A.; Bari, S.E.; Salido, E.; Chianelli, M.; Rosenstein, R.E. Effect of nitroxyl on the hamster retinal nitridergic pathway. Neurochem. Int. 2007, 51, 424-432. [CrossRef] [PubMed]

46. Väänänen, A.J.; Moed, M.; Tuominen, R.K.; Helkamaa, T.H.; Wiksten, M.; Liesi, P.; Chiueh, C.C.; Rauhala, P. Angeli's Salt Induces Neurotoxicity in Dopaminergic Neurons In Vivo and In Vitro. Free. Radic. Res. 2003, 37, 381-389. [CrossRef] [PubMed]

47. Vanin, A.F. What is the Mechanism of Nitric Oxide Conversion into Nitrosonium Ions Ensuring S-Nitrosating Processes in Living Organisms. Cell Biochem. Biophys. 2019, 77, 279-292. [CrossRef] [PubMed]

48. Zhitkovich, A. N-Acetylcysteine: Antioxidant, Aldehyde Scavenger, and More. Chem. Res. Toxicol. 2019, 32, 1318-1319. [CrossRef] [PubMed]

49. Pocernich, C.B.; Cardin, A.L.; Racine, C.L.; Lauderback, C.M.; Butterfield, D.A. Glutathione elevation and its protective role in acrolein-induced protein damage in synaptosomal membranes: Relevance to brain lipid peroxidation in neurodegenerative disease. Neurochem. Int. 2001, 39, 141-149. [CrossRef]

50. Pocernich, C.B.; Butterfield, D.A. Elevation of glutathione as a therapeutic strategy in Alzheimer disease. Biochim. Biophys. Acta Mol. Basis Dis. 2012, 1822, 625-630. [CrossRef]

51. Wrotek, S.; Jędrzejewski, T.; Piotrowski, J.; Kozak, W. N -Acetyl- 1 -cysteine exacerbates generation of IL-10 in cells stimulated with endotoxin in vitro and produces antipyresis via IL-10 dependent pathway in vivo. Immunol. Lett. 2016, 177, 1-5. [CrossRef] [PubMed]

52. Pilz, L.K.; Trojan, Y.; Quiles, C.L.; Benvenutti, R.; Melo, G.; Levandovski, R.; Hidalgo, M.P.L.; Elisabetsky, E. Effects of $\mathrm{N}$-acetylcysteine and imipramine in a model of acute rhythm disruption in BALB/c mice. Chronobiol. Int. 2015, 32, 248-254. [CrossRef] [PubMed]

53. Ledezma, C.; Coria-Lucero, C.; Delsouc, M.B.; Casais, M.; Della Vedova, C.; Ramirez, D.; Devia, C.M.; Delgado, S.M.; Navigatore-Fonzo, L.; Anzulovich, A.C. Effect of an Intracerebroventricular Injection of Aggregated Beta-amyloid (1-42) on Daily Rhythms of Oxidative Stress Parameters in the Prefrontal Cortex. Neuroscience 2021, 458, 99-107. [CrossRef] [PubMed]

54. Hill, B.G.; Bhatnagar, A. Protein S-glutathiolation: Redox-sensitive regulation of protein function. J. Mol. Cell. Cardiol. 2012, 52, 559-567. [CrossRef]

55. Naseri Kouzehgarani, G.; Bothwell, M.Y.; Gillette, M.U. Circadian rhythm of redox state regulates membrane excitability in hippocampal CA1 neurons. Eur. J. Neurosci. 2020, 51, 34-46. [CrossRef]

56. Schmalen, I.; Reischl, S.; Wallach, T.; Klemz, R.; Grudziecki, A.; Prabu, J.R.; Benda, C.; Kramer, A.; Wolf, E. Interaction of Circadian Clock Proteins CRY1 and PER2 Is Modulated by Zinc Binding and Disulfide Bond Formation. Cell 2014, 157, 1203-1215. [CrossRef]

57. Putker, M.; Crosby, P.; Feeney, K.A.; Hoyle, N.P.; Costa, A.S.; Gaude, E.; Frezza, C.; O'Neill, J.S. Mammalian Circadian Period, But Not Phase and Amplitude, Is Robust Against Redox and Metabolic Perturbations. Antioxid. Redox Signal. 2018, 28, 507-520. [CrossRef]

58. Pei, J.-F.; Li, X.-K.; Li, W.-Q.; Gao, Q.; Zhang, Y.; Wang, X.-M.; Fu, J.-Q.; Cui, S.-S.; Qu, J.-H.; Zhao, X.; et al. Diurnal oscillations of endogenous $\mathrm{H} 2 \mathrm{O} 2$ sustained by p66Shc regulate circadian clocks. Nat. Cell Biol. 2019, 21, 1553-1564. [CrossRef]

59. Miranda, K.M.; Dutton, A.S.; Ridnour, L.A.; Foreman, C.A.; Ford, E.; Paolocci, N.; Katori, T.; Tocchetti, C.G.; Mancardi, D.; Thomas, D.D.; et al. Mechanism of Aerobic Decomposition of Angeli's Salt (Sodium Trioxodinitrate) at Physiological pH. J. Am. Chem. Soc. 2005, 127, 722-731. [CrossRef]

60. Suarez, S.A.; Bikiel, D.E.; Wetzler, D.E.; Marti, M.A.; Doctorovich, F. Time-Resolved Electrochemical Quantification of Azanone (HNO) at Low Nanomolar Level. Anal. Chem. 2013, 85, 10262-10269. [CrossRef] 